\title{
Propuesta de una nueva promesa bioética para los científicos que emplean animales en sus investigaciones (Parte II) ${ }^{1}$
}

\section{Proposal for a new bioethical promise for scientists who use animals in their research (Part II)}

Recibido: 09 de marzo de 2015 - Revisado: 11 de noviembre de 2015 - Aprobado: 12 de abril de 2016.

Luis Fernando Garcés Giraldo ${ }^{2}$

Astelio Silvera Sarmiento ${ }^{3}$

J. Eduardo Murillo Bocanegra ${ }^{4}$

Jovany Sepúlveda-Aguirre ${ }^{5}$

\section{Resumen}

Se presenta una propuesta de promesa para los profesionales de las ciencias animales en Colombia y el mundo. El juramento que plantea el artículo 9 de la ley 576 de 2000 no es suficiente y no cumple con las condiciones bioéticas que debe tener un profesional del siglo actual. Se describe la metodología utilizada para la nueva promesa y se desarrolla esta promesa teniendo en cuenta la virtud aristotélica y las relaciones que debe tener el hombre, como ser racional, con todos los seres vivos y el cuidado que debe prodigar a estos. Se describe uno a uno los postulados que se incluyen dentro de la propuesta y el por qué fueron considerados.

\section{Palabras clave}

Promesa bioética, virtud, ley 576 de 2000, juramento, Aristóteles.

\begin{abstract}
A proposal of promise for professionals of the animal sciences in Colombia and the world is presented. The oath of article 9 of Law 576 of 2000 is not sufficient and does not meet the bioethical conditions that a professional of the present century must have. It describes the methodology used for the new promise and develops this promise taking into account the Aristotelian virtue and the relationships that man must have, as a rational being, with all living beings and the care that should be given to them. The postulates that are included within the proposal are described one by one as well as reasons why they were considered are described one by one.
\end{abstract}

\section{Keywords}

Bioethical promise, virtue, law 576 of 2000 , oath, Aristotle.
1 Artículo de reflexión derivado de investigación de la tesis del doctorado en Filosofía "Bioética en la experimentación con animales a partir de la ética de Aristóteles. Una reflexión filosófica para el cuidado de lo otro", de Luis Fernando Garcés Giraldo, Universidad Pontificia Bolivariana, Medellín, Colombia.

${ }^{2} \mathrm{Ph}$. D en Filosofía de la Universidad Pontificia Bolivariana. Docente Investigador de la Corporación Universitaria Americana Medellín, Colombia. Integrante del Grupo de Investigación: "Derecho, justicia y estado social de derecho" de la Facultad de Humanidades y Ciencias Sociales de la misma institución. Correo electrónico:

lgarces@americana.edu.co

${ }^{3} \mathrm{Ph}$. D. en ciencias de la educación de la Universidad Simón Bolívar. M.Sc. en educación de la Universidad del Atlántico-SUE Caribe. Vicerrector Nacional de Investigaciones de la Corporación Universitaria Americana, Medellín, Colombia. Investigador asociado y Docente de Maestría en Educación y Especialización en Pedagogía de las Ciencias en la Universidad Simón Bolívar. Correo electrónico: asilvera@coruniamericana.edu.co

${ }^{4}$ Ph.D. en Administración de negocios de la University of Missouri, Missouri, Estados Unidos. M.Sc. en Artes y Antropológia Cultural de la University of Missouri, Missouri, Estados Unidos. Rector de la Corporación Universitaria Lasallista, Caldas - Antioquia, Colombia. Correo electrónico: rector@1asallista.edu.co ${ }^{5}$ M.Sc. en Gestión de la Innovación Tecnológica, Cooperación y Desarrollo Regional del Instituto Tecnológico Metropolitano. Vicerrector de investigación de la Corporación Universitaria Americana, Medellín, Colombia. Correo electrónico:

vicerrectorinvmed@coruniamericana. edu.co

Para citar este artículo use: Garcés, L., Silvera, A., Murillo, E., \& SepúlvedaAguirre, J. (2016).. Propuesta de una nueva promesa bioética para los científicos que emplean animales en sus investigaciones (Parte II). Civilizar Ciencias Sociales y Humanas, 16(31), 249-262. 


\section{Introducción}

Se tiene como base de la discusión el artículo escrito en la Revista Civilizar Ciencias Sociales y Humanas volumen 16, número 30 denominado "Juramentos y promesas de profesionales de las áreas que trabajan con animales. Fundamentación para una promesa bioética de los científicos que experimentan con animales (Parte I)", allí se realizó un análisis de los juramentos y promesas que existen en algunos países, desde el juramento hipocrático para los médicos de la medicina de los humanos hasta los juramentos latinoamericanos sobre los profesionales de las ciencias humanas.

Es así como se plantea que el juramento para los médicos veterinarios, los médicos veterinarios zootecnistas y los zootecnistas que se encuentra vigente en Colombia es el consagrado en el artículo 9 de la ley 576 de 2000, sobre el Código de Ética para el Ejercicio Profesional de la Medicina Veterinaria y Zootecnia. El siguiente es el juramento con el que se consagran estos profesionales el día de su graduación.

\footnotetext{
Juramento para Colombia de los médicos veterinarios, médicos veterinarios zootecnistas y zootecnistas (artículo 9, ley 576 de 2000).

Juro, en el nombre de Dios, cumplir la Constitución y las leyes de mi patria y todas las obligaciones inherentes a la profesión de medicina de los animales y la zootecnia.

Protegeré al hombre de las enfermedades que los animales puedan transmitir, y emplearé las técnicas necesarias para obtener de los animales los alimentos que lo beneficien, respetando los ecosistemas y evitando riesgos secundarios para la sociedad y su hábitat mediante el uso de insumos yprácticas con tecnologías limpias, defendiendo la vida en todas sus expresiones.

Honraré a mis maestros, hermanaré con mis colegas y enseñaré mis conocimientos dentro de la misión científica con generosidad y honestidad.

Prometo estudiar y superarme permanentemente para cumplir con eficiencia la labor profesional encomendada.

Enalteceré mi profesión cumpliendo bien, siempre y en todo momento, las normas y preceptos de la Ley de Ética Profesional.
}

Este juramento debe ser modificado considerando las relaciones de los seres vivos en la actualidad y la importancia de recuperar el legado ético de los antiguos griegos como es la virtud aristotélica. Se requiere para los tiempos que corren una promesa bioética que contemple las relaciones entre los seres vivos, sin olvidar al ser humano como ser preeminente en la naturaleza, dotado de racionalidad y sensibilidad frente a otras formas de vida.

\section{Juramento o promesa: metodología para su construcción}

Es importante entender qué es un juramento y qué partes lo conforman. En general, un juramento es un compromiso público que hacen los profesionales y que contiene unos principios para actuar éticamente en la profesión. Para Have (2010):

[...] un juramento es un llamado a un principio o a una serie de principios que deben ser universalizables, es decir, que puedan ser aplicados a todos los individuos en circunstancias similares. Así, el juramento es una forma privilegiada de asegurar que las personas se involucren personalmente y se obliguen abiertamente, a través de un compromiso público que se constituye por la declaración de principios éticos que cada uno acepta cumplir (p. 25).

Los juramentos o códigos de conducta requieren al menos tres elementos: a) la forma, es la manera como está escrito el juramento como combinación de prohibiciones o amonestacio- 
nes; b) el contenido, identifica aspectos principales $^{1}$ o virtudes que se espera encontrar en las normas para el comportamiento de las personas; y c) la función, intenta dar ejemplos de la moralidad interna de la ciencia para establecer el valor social de esta (Have, 2010, p. 24). Otro modo de mirar el contenido de un juramento es el que ofrece Del Olmo (2010): "Un juramento consta de la siguiente estructura: una introducción o cláusula inicial ${ }^{2}$; unos compromisos ${ }^{3}$ y terapéuti$\mathrm{ca}^{4} ; \mathrm{y}$ unas conclusiones o cláusula final”' (p. 1).

Otro factor para explorar es la forma como están escritos algunos juramentos. Los enunciados de los juramentos o promesas en la formulación de sus postulados deben hacerse de manera positiva y no negativa, como existe en muchos juramentos. Gustafsson, Rydén, Tibell, y Wallensteen (2010) estiman que "estos deberían establecer lo que los científicos deben hacer, en lugar de lo que no deben” (p. 36).

Es por esto que en los últimos tiempos se ha visto la necesidad de que se tenga una promesa de carácter ético para los científicos en el momento de su graduación, principalmente por el gran avance de la ciencia en las últimas décadas. Hallberg (2010) hablando de la urgencia de contar con promesas éticas desde los científicos, dice: "La finalidad principal es la concienciación sobre los posibles usos y aplicaciones del conocimiento, la búsqueda de una actitud ética, socialmente responsable y en beneficio de la humanidad" (p. 111).

Se emplean indistintamente las palabras juramento y promesa, de acuerdo con la revisión realizada, unos autores usan juramento y otros promesa, en muchos de los casos las manejan como expresiones que tienen el mismo significado. Miremos algunas diferencias entre ellas. Según el Diccionario de la Real Academia de la Lengua Española, se entiende por juramento, la afirmación o negación de algo, poniendo por testigo a Dios, o en sí mismo o en sus criaturas; también se entiende como voto o reniego; y por promesa, el ofrecimiento solemne, sin fórmula religiosa, pero equivalente al juramento, de cumplir bien los deberes de un cargo o función que va a ejercerse. Lemarchand (2010), refiriéndose a la diferencia que puede existir entre juramento y promesa, indica que:

Ambas comparten las características esenciales de mantener los elementos importantes del testimonio, la promesa, la palabra de honor o la garantía. Puesto que estos términos son de uso general, los juramentos y las promesas suelen ser afirmaciones públicas de un compromiso a mantener ciertos principios específicos o responsabilidades (p. 68).

Se usará entonces el vocablo "promesa" por encontrarlo más universal, por ser un término solemne sin fórmula religiosa y por ser una promesa personal y un compromiso profesional ético de cumplir con responsabilidad los principios profesados, mientras que el juramento debe poner por testigo a alguien. También usaremos, en la construcción de la promesa para los profesionales de las ciencias animales la forma metodológica que propone Del Olmo, es decir, que contenga una introducción o cláusula inicial, unos compromisos y terapéutica y unas conclusiones o cláusula final. Además, la promesa se redactará de manera positiva.

\section{Promesa para los científicos que trabajan con animales}

En el preámbulo de la "Declaración sobre la ciencia y el uso del saber científico y programa en pro de la ciencia" -emitida por la $30^{\mathrm{a}}$ Conferencia General de la Organización de las Naciones Unidas para la Educación, la Ciencia y la Cultura que se celebró en París en 1999- se habla sobre la importancia de la preservación de los sistemas de vida: "Que la prosecución de la ciencia y el uso del saber científico deben respetar y preservar todas las formas de vida y los sistemas de sustentación de la vida de nuestro planeta" (numeral 23).

Además, en el numeral 43 establece que: "Todos los investigadores deberían comprome- 
terse a acatar normas éticas estrictas y habría que elaborar para las profesiones científicas un código deontológico basado en los principios pertinentes consagrados en los instrumentos internacionales [...]" y en el numeral 76 se habla de que los gobiernos, las organizaciones no gubernamentales y más concretamente las asociaciones científicas, deben organizar debates para que se adopten códigos deontológicos para los miembros de las comunidades científicas.

Es así como una promesa para los profesionales de las ciencias animales, debe representar una aceptación de la toma de conciencia para que las acciones y deliberaciones del trabajo en la experimentación con animales tengan una dimensión ética. La responsabilidad profesional y científica es el lugar donde debe darse la reflexión bioética, interdisciplinaria, plural y democrática con amplia participación de todos los interesados. Al respecto, Vidal (2010) nos cuenta: "En esa responsabilidad es precisamente donde subyace la reflexión ética y bioética que desde ya es más que una deontología de los científicos para devenir en un diálogo" (p. 140). Friedrich (2010), hablando de la promesa y de su carácter ético, señala que:

[...] es un compromiso público que hacen los que van a iniciar sus prácticas con pacientes o se gradúan en Medicina, Fisioterapia u Odontología; lo hacen igualmente otras personas del área de la salud. En Veterinaria se hace ante otros médicos veterinarios, y ante la comunidad. Su contenido es de carácter ético y se fundamenta en la responsabilidad y conciencia que debe orientar la práctica de la ciencia y el arte de curar (p. 33).

La promesa que se propondrá tendrá, sin duda alguna, los principios del personalismo ontológico seleccionados ${ }^{6}$ dentro del modelo bioético y las virtudes aristotélicas discutidas; para Gracia (2004b): “[...] la tesis griega es que un buen profesional es aquel que tiene la areté propia de su actividad. El profesional tiene que ser un hombre virtuoso; que es el paradigma de la excelencia" (p. 248), es decir, del hombre excelente que hace de sus actos cosas buenas, no reprobables.

\section{Propuesta de promesa para los científicos de las ciencias animales}

Como profesionales de las ciencias animales entendemos que nos encontramos ante una relación de interdependencia entre los seres humanos y los animales, y que debemos propender por la preservación de los sistemas de sustentación $\mathrm{y}$ de la supervivencia de todas las formas de vida en el planeta.

Nos comprometemos a:

Enaltecer al ser humano como ser preeminente en la naturaleza, centro de todas las consideraciones bioéticas, fin y no medio. Actuar con responsabilidad y libertad en la defensa de todas las formas de vida y en especial la de los seres humanos.

Proteger a los animales que comparten con los seres humanos la vida en el planeta y darles un trato apropiado para no causarles sufrimiento, daño o dolor.

Procurar que los actos en la experimentación con animales sean prudentes, es decir, que estén mediados por la recta razón, la sensatez, el discernimiento y el buen obrar, evitando las actuaciones precipitadas e impulsivas.

Utilizar el saber práctico, la técnica -el arte del científico- para saber hacer y saber obrar sin hacerles daño a los animales que son objetos de intervención en la experimentación.

Obrar con sabiduría para conocer los principios y las causas del saber científico, es decir, saber cómo usar el conocimiento para la supervivencia de las especies con beneficio social.

Actuar con justicia para deliberar sobre lo que es bueno, sobre todo aquello que haga el bien a la naturaleza donde se incluyen los seres humanos y los animales.

Comprender que la razón para la toma de decisiones en la experimentación con animales, debe estar mediada por actos continentes, sin apasionamientos ni deseos que lleven a cometer actos lesivos para la supervivencia de las especies.

Cumplir con los principios de las tres erres, siempre que sea posible, sin disminuir la calidad y validez de la investigación: reducir el número de animales empleados, refinar las técnicas para minimizar el sufrimiento animal y remplazar el animal vivo por técnicas experimentales alternativas.

Hago esta promesa de manera pública, solemne y espontáneamente como profesional de las ciencias animales, para lo cual trabajaré y me formaré con responsabilidad social, bioética y ambiental. Cumpliré con los compromisos de esta promesa y de las normas establecidas en mi país para este tema y que vayan en beneficio de la salud humana y animal. 
De acuerdo con la metodología de la elaboración de la promesa que aquí nos ocupa, su justificación es la siguiente:

\section{Introducción o cláusula inicial.}

Como profesionales de las ciencias animales entendemos que nos encontramos ante una relación de interdependencia entre los seres humanos y los animales, y que debemos propender por la preservación de los sistemas de sustentación y de la supervivencia de todas las formas de vida en el planeta.

Los problemas nos afectan en la actualidad a todos por igual. La ciencia es una parte sustancial de nuestras vidas. Muchas discusiones ético-políticas o ético-jurídicas relevantes suponen y requieren conocimiento en diferentes áreas como la biología, la genética, la neurología, la ecología, entre otras (Llopis, 2003, p. 221). Potter enmarca la bioética en un sistema moral que relaciona los conocimientos biológicos y los valores humanos, donde los seres humanos deben aceptar la responsabilidad de la supervivencia biológica y cultural, por nuestra supervivencia y la del resto de las especies, y por la preservación del medioambiente (GarcíaRodríguez, Delgado, \& Rodríguez-León, 2009, p. 879).

El surgimiento de la bioética trae consigo un rediseño del complejo horizonte de integración entre el conocimiento y el valor; en pos de una mejor reflexión acerca de la instrumentalización de la vida por parte del saber científico, la bioética opera un nuevo reporte normativo entre los científicos y sus acciones (Villaroel, 2009, p. 81).

Es así como la bioética propende por el respeto a la vida y la dignidad humana, pues se encuentra estrechamente ligada al concepto de libertad. Tal libertad es cada vez más restringida debido a las consecuencias desbordantes e indeseables de los avances tecnológicos. La muerte de los mares, la constante contamina- ción del aire respirable, la lluvia ácida y la acelerada extinción de especies alteran de forma grave la calidad de vida, y constituyen alertas tempranas a un panorama que puede ser más irreversible para el futuro de la vida en el planeta. Esto, debido al consumo cada vez más insensato de nuestros recursos, lo que genera un grave deterioro ambiental, afecta la calidad de la vida en la Tierra, altera peligrosa y aceleradamente el equilibrio en nuestro planeta $\mathrm{y}$, en consecuencia, cuestiona la supervivencia de la especie humana (Palacio, 2008, p. 54).

\section{Compromisos y terapéutica.}

"Enaltecer al ser humano como ser preeminente en la naturaleza, centro de todas las consideraciones bioéticas, fin y no medio". Alude al principio de la defensa de la vida para la bioética personalista ontológica ${ }^{7}$. Para Díaz (2009):

La claridad del fin permite definir la conveniencia del medio ${ }^{8}$. Así el poder establecer el sentido de la vida humana y de las prácticas que impactan la vida en todas sus formas, es un recurso válido para la bioética en la medida que de allí puede derivar los criterios para su tarea propiamente ética (p. 117).

Según Sgreccia (2013) "La persona humana es artífice de la sociedad y de la biósfera, es artífice del ambiente ecológico y social, por el cual es, a su vez, condicionada y estimulada" (p. 121).

"Actuar con responsabilidad y libertad en la defensa de todas las formas de vida y en especial la de los seres humanos". Atañe al principio de la libertad y responsabilidad en la bioética personalista ontológica. Es necesario para los tiempos venideros que se entienda la relación de los seres humanos con la biósfera, indagando sobre los mecanismos de prevención de la naturaleza, además de identificar el lugar del ser humano y las consecuencias y el sentido de sus actos sobre el ecosistema. Para Aliciardi (2009): 
La bioética debe ser el producto libre de un constructo social con base en el conocimiento científico y en la experiencia sapiencial, que negocie consensos que dignifiquen la vida humana y permitan mejorar la calidad de vida de todos en armonía con la naturaleza (p. 13).

"Proteger a los animales que comparten con los seres humanos la vida en el planeta y darles un trato apropiado para no causarles sufrimiento, daño o dolor". Corresponde al principio de solidaridad y subsidiariedad en el modelo bioético personalista ontológico. Se debe evitar al máximo el sufrimiento de los animales en la experimentación; al respecto, Cardozo y Mrad (2008) se refieren a los principios éticos en el uso y cuidado que los investigadores deben tener con los animales, así:

La primera condición del investigador que trabaja con animales de laboratorio es el respeto por la vida, por el dolor o el sufrimiento a que estos pueden ser sometidos en los trabajos bajo su responsabilidad. Siempre que se utilicen animales en investigaciones habremos de considerar que un objetivo tan importante como el de obtener resultados experimentales será el de minimizar cualquier dolor o angustia que estos puedan sufrir. El refinamiento de los procedimientos para conseguir que sean más humanos debe ser parte integrante de toda investigación científica (p. 63).

Para Sánchez (2002, p. 110): “Los actos humanos que afectan a los animales son, por eso mismo, actos morales, entendiendo el acto moral como aquel que puede ser justificado de ser realizado por un agente moral autónomo y libre” (p. 110). En Rodríguez (2008):

Los animales no son iguales que cualquier objeto inanimado. Estos seres vivos no solo tienen una existencia evidente sino que, además, como ha sido comprendido por estudiosos, cuentan con emociones y son susceptibles de irritarse, agredir, respetar o violar territorios (p. 310).

El derecho a la vida que les asiste a los animales con los que cohabitamos la Tierra no puede, ni debe, reducirse a un simple asunto legal o a un disenso sobre lo cultural; el problema trasciende los estrados y las tradiciones y se instala en lo que desde la sostenibilidad se entiende como ética. Para Vásquez y Navarrete (2010):

[...] la ética en la visión de sostenibilidad es un enfoque fundamental que trasciende ideologías, sectarismos o cualquier tipo de actitud o síntoma de grupo cerrado; es, en realidad, un compromiso de trabajo humanístico, por la vida, el respeto al medio y a la naturaleza. Es, si se quiere, una filosofía de convivencia con las más profundas raíces de permanencia civilizada, con los congéneres y el resto de especies que habitan este planeta, independientemente de las fronteras (p. 41).

"Procurar que los actos en la experimentación con animales sean prudentes, es decir, que estén mediados por la recta razón, la sensatez, el discernimiento y el buen obrar, evitando las actuaciones precipitadas e impulsivas". El hombre de ciencia, y en especial el científico que experimenta con animales, debe tener una excelente razón práctica para relacionar la acción con la deliberación. La prudencia permite al hombre que la posee reflexionar adecuadamente y llegar a decisiones correctas.

En síntesis, la phrónesis, entendida como una disposición acompañada de la prescripción ética correcta, es la que hace posible evaluar adecuadamente, durante la deliberación, las diferentes opciones que se presentan y tomar decisiones cabales en cuanto al valor de la naturaleza, la responsabilidad que el hombre tiene con ella y, por supuesto, el valor del ser humano en la naturaleza misma (López, 2008, p. 73).

Los avances en la investigación científica son importantes para el desarrollo de los pueblos, pero es necesario que los científicos y la sociedad tomen conciencia de que el desarrollo se debe hacer para el bien de la humanidad y con la responsabilidad ética que como seres humanos nos corresponde con los 
seres que cohabitamos este planeta. Es por esto que la actitud prudencial del investigador que experimenta con animales lo debe llevar a tomar medidas efectivas para que se haga el menor daño posible a estos seres vivos.

"Utilizar el saber práctico, la técnica -el arte del científico- para saber hacer y saber obrar sin hacerles daño a los animales que son objetos de intervención en la experimentación". Es menester entender la técnica, en la actualidad, como

[...] una necesidad del hombre: la técnica es natural en el hombre, es vida humana. El error reside en pensar que ella nos ha liberado de la realidad al habernos independizado de la naturaleza, olvidando que el estar abiertos a la realidad es lo que ha permitido desarrollar la técnica (Bota, 2007, p. 63).

El hombre ha estado abierto a la realidad, no únicamente como posibilidad sino como realización (Bota, 2007). Esparza citado en Montoya (2008) considera que "la técnica en sí misma, como un fenómeno consustancial a la propia existencia de la especie humana [...] La técnica es nuestra naturaleza; es la forma humana de estar en el mundo, sin técnica no hay humanidad propiamente dicha" (p. 299).

Es así como a la técnica hay que entenderla en toda su dimensión: como un proceso de articulación del hombre con la naturaleza a través del cual este se realiza en la misma, la comprende y se comprende a sí mismo, lo que implica que es un acto no instintivo ni mecánico sino dialéctico y con conocimiento de la razón de ser de dicha integración (Montoya, 2008).

La experimentación con animales debe estar mediada por el carácter humano del científico, por su experienca profesional; debe verse como un arte para que este pueda transmitir sentimientos y emociones y despertar la magia interior del científico. En el libro I de la Metafisica, Aristóteles sostiene que nace el arte (téchne) cuando de las muchas observaciones expe- rimentales surge una noción universal sobre los casos semejantes (Innerarty, 2008, p. 83).

"Obrar con sabiduría para conocer los principios y las causas del saber científico, es decir, saber cómo usar el conocimiento para la supervivencia de las especies con beneficio social". La sabiduría, en sus múltiples modalidades, es una necesidad vital y una curiosidad, una aprehensión de la realidad por medio de la cual esta queda fijada en el sujeto (Gervilla, 2006, p. 1048). Toda ciencia tiene, en sí misma, la posibilidad de ser atraída por la sabiduría, toda vez que desde la especificidad de su campo es capaz de elevarse a la consideración de las primeras causas, causas en las que todas las ciencias resuelven sus principios (Caponnetto, 2000, p. 4).

Actuar conforme con la virtud debe ser para el hombre, y en particular para el científico que experimenta con animales, una disposición permanente a obrar con sabiduría, como conocedor de los principios de la naturaleza y en especial de aquellas cosas que involucran el trato con los animales que serán objeto de investigación. Es del sabio aristotélico, y sobre todo del científico que experimenta con animales, conocer los principios universales que se han establecido para un uso más racional de estos seres vivos.

"Actuar con justicia para deliberar sobre lo que es bueno, sobre todo aquello que haga el bien a la naturaleza donde se incluyen los seres humanos y los animales". La virtud, y en especial la de la justicia, debe estar regulada por la recta razón para deliberar sobre lo que es bueno, sobre todo aquello que haga el bien. El virtuoso aristotélico debe buscar que sus actos estén mediados por la voluntad para elegir lo que es justo, no para sí mismo, sino para el bien común; este, como ya lo hemos discutido, es el principio rector de la virtud de la justicia: querer practicar lo que es justo; obrar con justicia -y como lo dice Aristóteles, en la justicia se encuentran incluidas todas las virtudes- es la 
práctica de la virtud perfecta porque se es justo con los otros y con lo otro; las otras virtudes perfeccionan el bien individual, mientras que la justicia se orienta a la polis; es, por tanto, la virtud del buen ciudadano.

Un hombre virtuoso obra haciendo no solamente lo que es apropiado en diversas circunstancias de la vida, sino haciéndolo en el modo justo, con una adecuada disposición interior hacia todo lo que lo rodea, en especial, hacia la naturaleza (Díaz, 2009, p. 103). El ser humano no puede degradar su dignidad con una conducta que no tenga en cuenta a los seres vivos, entre ellos los animales y su sufrimiento, y si lo permite o lo produce, ha de ser por razones suficientemente serias (Pardo, 2005, p. 406).

El investigador justo, por ende, debe racionalizar adecuadamente la inversión que la sociedad ha puesto en sus manos para ejecutar solo aquellos proyectos que tengan pertinencia y relevancia para el conocimiento y para la comunidad. Al remplazar los animales y reducir su uso a lo más mínimo, con el objetivo de hacerles menos daño, está expresando el respeto por otras formas de vida, las cuales utilizará y cuidará (Cardozo \& Mrad, 2008, p. 66).

"Comprender que la razón para la toma de decisiones en la experimentación con animales, debe estar mediada por actos continentes, sin apasionamientos ni deseos que lleven a cometer actos lesivos para la supervivencia de las especies". Es así como para los profesionales que hacen uso de animales para la experimentación, actuar según la virtud de la continencia debe ser una disposición permanente para que sus acciones, que deben ser mediadas por la recta razón y sin exceder los deseos y el apetito, puedan, dentro de su ciencia, ser buenas para el beneficio de los seres vivos que están interviniendo con sus ensayos que, sin duda alguna, son de vital importancia para el provecho y la salud del hombre.

Es por ello que este científico debe tener conocimiento en el tema de experimentación, dado por su práctica continua y por su inclinación a aprender y formar hábitos que son necesarios para la adquisición de la virtud. A ser un científico virtuoso se debe aprender con cada uno de los actos que realice, con un constante entrenamiento sobre aspectos bioéticos para el manejo de los animales de los cuales hace uso para la investigación científica.

En síntesis, los hábitos que forman el carácter son valiosos porque predisponen el sujeto para desear y reconocer las acciones buenas, esto se da en la continencia; el continente es capaz de sobreponerse a los deseos que le han sido dados por sus hábitos y suscitados por las circunstancias particulares en las que se desenvuelve la acción (Morales, 2010, p. 85). Una de las capacidades que tiene el ser humano es el saber elegir sus actos.

La elección de un bien corresponde a los racionales, quienes comparten con los irracionales el apetito por las cosas, pero se distinguen en este punto por una condición moral, la de la continencia, que falta a los irracionales. Así para Aristóteles, cuando el individuo racional domina las partes del alma para que sigan un razonamiento derecho, la elección es libre, sin estar determinada por el apetito. Cuando falta esta condición moral de la continencia, el individuo racional actúa según sus apetitos (Parrilla, 1999, p. 235).

\section{Conclusiones o cláusula final de la promesa.}

Hago esta promesa de manera pública, solemne y espontáneamente como profesional de las ciencias animales, para lo cual trabajaré y me formaré con responsabilidad social, bioética y ambiental. Cumpliré con los compromisos de esta promesa y de las normas establecidas en mi país para este tema y que vayan en beneficio de la salud humana y animal.

Todo profesional que experimenta con animales debe tener una capacidad moral que es su valor como persona, lo cual da dignidad, seriedad y nobleza a su labor; de allí su trascen- 
dencia, esto es, su aptitud para abarcar y llevar su esfera profesional a un horizonte mucho más amplio, que lo hace valer como persona fuera y dentro de su trabajo; debe desarrollar aquellas virtudes que le permitan ejercer su profesión dignamente para llegar a ser una persona íntegra: justicia, responsabilidad, discreción y honestidad (Hernández, 2010, p. 80).

La ética es necesaria en la formación profesional, porque constituye un soporte del desarrollo de la personalidad y del carácter del sujeto, elementos estos que hoy en día se consideran componentes estructurales de las capacidades profesionales. La ética coadyuva a moldear la personalidad y el carácter del profesional al dotarlo de principios y valores morales que norman su comportamiento y que posibilitan un proceder ético en su quehacer profesional. Así mismo, le proporciona el criterio y el juicio ético que también contribuyen a fortalecer sus capacidades profesionales, puesto que tienen un papel activo en la toma de decisiones (Ibarra, 2007, p. 4).

La ética se necesita como una reflexión constante para poder orientar nuestro actuar con libertad y responsabilidad hacia una finalidad que debe ser la realización del ser humano, así como para saber si nuestras acciones son buenas o malas; además, lleva implícitos valores que son necesarios para una sana convivencia y para frenar las tendencias destructivas del ser humano frente a la naturaleza y a él mismo.

El investigador debe tomar en cuenta las estrategias para el uso de animales en experimentación propuestas por Russell y Burch quienes introdujeron normas alternativas conocidas como "las tres erres" que para su comprensión y aplicación se definen como: reducir del número de animales sin disminución de la precisión, con métodos para obtener niveles comparables de información, a partir del uso de pocos animales en los procedimientos científicos, remplazar: sustitución de animales conscientes por animales no conscientes o materiales no sensi- bles: agrupan aquellos métodos que permiten realizar experimentos sin el uso de animales vivos por técnicas experimentales alternas; refinar las técnicas para reducir el dolor y el malestar, donde agrupan aquellos métodos que alivian o minimizan el dolor y la angustia para mantener el bienestar animal (Sánchez, 2000, p. 207); esto con la finalidad de generarle al animal de experimentación el menor sufrimiento o daño posible.

Antes de pasar a las conclusiones finales, parece oportuno señalar que lo realizado aquí constituye una propuesta de formulación de un nuevo estatuto bioético, que podría ser aceptado luego de una revisión por parte de la comunidad académica y por la legislación, por supuesto, en el caso específico de la experimentación con animales.

Con seguridad, serán interesantes los efectos de la propuesta de un nuevo compromiso o promesa bioética para los científicos que emplean animales en sus investigaciones. Más que elemento integrante de un ritual de graduación, se sugiere como excusa para reflexionar, a través de su lectura y escucha, en torno a la manera como el científico que emplea animales en su experimentación debe relacionarse con estos seres que son mucho más que cosas que, aunque diferentes a nosotros, merecen nuestro cuidado y respeto, porque su modo de ser y de vivir se entrelaza constantemente con el nuestro y no solamente en una relación de utilidad sino de compañía, de presencia y de evidencia de lo inefable en la realidad que compartimos.

\section{Conclusión}

En esta reflexión se revisó el juramento que existe en el artículo 9 de la ley 576 de 2000 sobre el Código de Ética para el Ejercicio Profesional de la Medicina Veterinaria y Zootecnia, y se encontró que es un juramento muy tecnicista que no incluye aspectos bioéticos importantes para el funcionamiento actual y las necesidades de esta disciplina. La promesa que se plantea 
contiene los principios del personalismo ontológico, las virtudes y los principios universales de las tres erres.

Esta promesa consta de tres partes: a) una introducción o cláusula inicial, donde se describe la interdependencia que existe entre los seres humanos y los animales para la preservación de los sistemas de sustentación y de la supervivencia del hombre; b) unos compromisos, donde se establecen postulados que abarcan los principios de la bioética personalista ontológica y las virtudes aristotélicas seleccionadas para el modelo bioético, además del compromiso de cumplir con los principios universales de las tres erres; y c) unas conclusiones o cláusula final, donde el profesional de las ciencias animales afirma que todos los compromisos de la promesa los hace de manera pública, solemne y espontánea cumpliendo con las normas y las responsabilidades adquiridas en el ejercicio profesional.

\section{Notas}

${ }^{1}$ Have (2010) afirma que los elementos principales por lo general son: "honestidad, franqueza, imparcialidad, veracidad, exactitud, escrupulosidad, respeto, colaboración, fidelidad, responsabilidad social, responsabilidad medioambiental, desarrollo sostenible, desarrollo socioeconómico, equidad de género, libertad científica, paz, desarrollo democrático [y] derechos humanos" (p. 24).

2 Para el juramento hipocrático este aspecto es el siguiente: "Juro por Apolo médico, por Esculapio, Higia y Panacea, por todos los dioses y todas las diosas, tomándolos como testigos, cumplir fielmente, según mi leal saber y entender, este juramento y compromiso".

${ }^{3}$ En el Juramento hipocrático se desarrolla en: "Venerar como a mi padre a quien me enseñó este arte, compartir con él mis bienes y asistirles en sus necesidades; considerar a sus hijos como hermanos míos, enseñarles este arte gratuitamente si quieren aprenderlo; comunicar los preceptos vulgares y las enseñanzas secretas y todo lo demás de la doctrina a mis hijos y a los hijos de mis maestros y a todos los alumnos comprometidos y que han prestado juramento, según costumbre, pero a nadie más".

4 Para el Juramento hipocrático se demuestra en: "En cuanto pueda y sepa, usaré las reglas dietéticas en provecho de los enfermos y apartaré de ellos todo daño e injusticia. Jamás daré a nadie medicamento mortal, por mucho que me soliciten, ni tomaré iniciativa alguna de este tipo; tampoco administraré abortivo a mujer alguna. Por el contrario, viviré y practicaré mi arte de forma santa y pura. No tallaré cálculos sino que dejaré esto a los cirujanos especialistas. En cualquier casa que entre, lo haré para bien de los enfermos, apartándome de toda injusticia voluntaria y de toda corrupción, principalmente de toda relación vergonzosa con mujeres y muchachos ya sean libres o esclavos. Todo lo que vea y oiga en el ejercicio de mi profesión, y todo lo que supiere acerca de la vida de alguien, si es cosa que no debe ser divulgada, lo callaré y lo guardaré con secreto inviolable".

${ }^{5}$ En el Juramento hipocrático se encuentra en: "Si el juramento cumpliere íntegro, viva yo feliz y recoja los frutos de mi arte y sea honrado por todos los hombres y por la más remota posteridad. Pero si soy transgresor y perjuro, avéngame lo contrario".

${ }^{6}$ Los principios del personalismo ontológico que se utilizarán en el modelo bioético propuesto son: el principio de la defensa de la vida física, el principio de la libertad y la responsabilidad, y el principio de la solidaridad y la subsidiariedad. Se aclara que el principio de la totalidad o terapéutico no se propone para la construcción de este modelo bioético por cuanto es un principio que se funda en el hecho de la corporeidad humana como defensa del cuerpo humano ante una intervención de un paciente con el objetivo de salvar el todo o parte del cuerpo; es un principio muy específico de la te- 
rapia médica para humanos donde se requiere de consentimiento informado por parte del paciente, factor que es imposible en los animales.

7 Bioética personalista ontológica con fundamentación en la virtud, entendida como el estudio sistemático de las dimensiones éticas que incluye las decisiones, la conducta y las políticas públicas que inciden en las ciencias de la vida y del cuidado de la salud, es una disciplina importante porque establece criterios para evitar una instrumentalización técnicopolítica de la vida humana.

${ }^{8}$ En esta cita Díaz (2009) dice textualmente: "Una muestra sencilla de este aspecto lo encontramos en la experimentación o investigación con animales. En un momento se admite como finalidad de esta práctica la total disposición de las especies inferiores con miras a probar, ensayar y verificar procedimientos que pudieran reportar beneficios a los humanos. En este campo el fin de la investigación era ilimitado en cuanto que el bien esperado para el hombre aceptaba tratamiento de los animales en el laboratorio. Sin embargo, la creciente conciencia sobre el valor de la vida no humana, sobre el estatuto ético de los animales, sobre su protección y conservación, son factores que llaman la atención de la práctica investigativa con el fin de recomponer su fin propio. Si el telos de la experimentación con animales es el beneficio de los seres humanos también lo es el cuidado, respeto y protección de los seres implicados en su práctica. Por eso la práctica investigativa y experimental ha empezado a redefinirse obligando a una limitación en su modo de proceder a través de protocolos de buena práctica científica" (p. 117, nota 35 ).

${ }^{9}$ En la actualidad se plantea una cuarta erre, es la de reciclar, Montenegro y otros (2011) nos dice al respecto: "Más recientemente, se ha instalado una $4^{\mathrm{a}} \mathrm{R}$ : elReciclaje. Apunta a utilizar los animales de experimentación más de una vez para otros tantos fines. A modo de ejemplo: animales sin tratamiento previo excepto la eutanasia- que después de producida la exéresis de algunos órganos objeto de estudio, y debidamente conservados, se destinan a la alimentación de especies predadoras en centros de crianza y zoológicos.

\section{Referencias}

Aliciardi, M. B. (2009). ¿Existe una ecobioética o bioética ambiental?. Revista Latinoamericana de Bioética, 9(1), 8-27.

Bota, A. (2007). Animales transgénicos como organismos artificiales. Acta Bioethica, 13(1), 61-70. doi: 10.4067/S1726-569X 2007000100007

Caponnetto, M. (2000). Conocimiento, ciencia y sabiduría. Congregación para la educación Católica. Roma: Diócesis de Roma.

Cardozo, C. A., \& Mrad, A. (2008). Ética en investigación con animales: una actitud responsable y respetuosa del investigador con rigor y calidad científica. Revista Latinoamericana de Bioética, 8(2), 46-71.

DelOlmo, L. (2010). Ética profesional. Manabí: Universidad Técnica de Manabí.

Díaz, A. (2009). La ética de la virtud y la bioética. Revista Colombiana de Bioética, 4(1), 93-128.

Friedrich, N. (2013). El Juramento Hipocrático y los veterinarios. Información Veterinaria, 173, 33-35. Recuperado de http:// www.produccion-animal.com.ar/temas varios_veterinaria/139-juramento_hipocratico.pdf

Garcés, L. (2016). Juramentos y promesas de profesionales de las áreas que trabajan con animales. Fundamentación para una promesa bioética de los científicos que experimentan con animales (Parte I). Civilizar Ciencias Sociales y Humanas, 16(30), 261-272. 
García-Rodríguez, J., Delgado, C., \& Rodríguez -León, G. (2009). Bioética global. Una alternativa a la crisis de la humanidad. $S a$ lud en Tabasco, 15(2-3), 878-881.

Gervilla, E. (2006). El 'sabor del saber' y el saber académico actual. Revista de Educación, 340, 1039-1063.

Gracia, D. (2004a). Fundamentación y enseñanza de la bioética. Bogotá: El búho.

Gracia, D. (2004b). Como arqueros al blanco: estudios de bioética. Madrid: Triacastela.

Gustafsson, B., Rydén, L., Tibell, G., \& Wallensteen, P. (2010). El Código de Ética para Cientificos de la Universidad de Uppsala (Estudios y documentos de política científica de ALC, Vol. 2. Ciencia para la paz y el desarrollo: el caso del Juramento Hipocrático para Científicos). Montevideo: UNESCO.

Hallberg, K. (2010). Hacia una investigación ética en ciencias: el aporte de los físicos argentino. (Estudios y documentos de política científica de ALC, Vol. 2. Ciencia para la paz y el desarrollo: el caso del Juramento Hipocrático para Científicos). Montevideo: UNESCO.

Have, T. H. (2010). Hacia un juramento ético universal para cientificos (Estudios y documentos de política científica de ALC, Vol. 2. Ciencia para la paz y el desarrollo: el caso del Juramento Hipocrático para Científicos). Montevideo: UNESCO.

Hernández, J. (2010). La Ética profesional, ¿un problema ético del contador público?. Revista del Centro de Investigación de Ciencias Administrativas y Gerenciales, 7(1), 74-89.

Ibarra, G. (2007). Ética y valores profesionales. Reencuentro, 49, 43-50.
Innerarty, C. (2008).La comprensión aristotélica del trabajo. Navarra: Universidad de Navarra.

Lemarchand, G. A. (2010). Ciencia para la paz y en beneficio de la humanidad. El concepto del Juramento Hipocrático para Cientificos (Estudios y documentos de política científica de ALC, Vol. 2. Ciencia para la paz y el desarrollo: el caso del Juramento Hipocrático para Científicos). Montevideo: UNESCO.

Ley 576 de 2000. Por la cual se expide el Código de Ética para el ejercicio profesional de la medicina veterinaria, la medicina veterinaria y zootecnia y zootecnia. Diario Oficial No 43.897. Congreso de la República de Colombia, febrero de 2000.

Llopis, R. (2003). La bioética 'tercera cultura'. Un análisis desde la sociología de la ciencia. Cuadernos Bioéticos, 2(3), 217-227.

López, M. T. (2008). Bioética. El final del consenso. Azafea Revista Filosófica, 10, 51-74.

Montenegro, S., Gayol, M., \& Tarrés, M. (2011). Aspectos éticos de la investigación con animales. Revista Médica de Rosario, 77, 69-74.

Montoya, O. (2008). De la téchne griega a la técnica occidental moderna. Scientia et Technica, 14(39), 298-303.

Morales, P. (2020). El Juramento de Buenos Aires: una ética de derechos, deberes $y$ responsabilidades humanas para la ciencia (Estudios y documentos de política científica de ALC, Vol. 2. Ciencia para la paz y el desarrollo: el caso del Juramento Hipocrático para Científicos). Montevideo: UNESCO.

Organización de las Naciones Unidas -[ONU]. (1999). Declaración sobre la ciencia y el uso 
del saber científico y programa en pro de la ciencia (30 Conferencia General). París.

Palacio, D. (2008). Bioética y salud pública. Revista Javeriana, 749(144), 46-55.

Pardo, A. (2005). Ética de la experimentación animal. Directrices legales y éticas contemporáneas. Cuadernos de Bioética, 16(3), 393-417.

Parrilla, C. (1999). Fablar segunt la arte' en “La Celestina”. En F. Pedraza, G. Gómez \& R. González (Coords.), La Celestina V Centenario 1499-1999 (pp. 229-246). España: Universidad de Castilla-La Mancha.

Rodríguez, G. (2008). Animales... ¿En peligro de extinción o en peligro de que los extingamos?. Ius et Praxis, 14(1), 301-315. doi: 10.4067/S0718-00122008000100011

Sánchez, F. (2000). Ética en investigación biomédica. Nómadas, 13(1), 199-208.

Sánchez, M. A. (2002). El debate ético actual sobre la relación del hombre con los animales. En Lacadena, J. R. (Ed.), Los derechos de los animales (pp. 109-131). Bilbao: Desclée de Brouwer.

Sgreccia, E. (2013). Persona humana y personalismo. Cuadernos de Bioética, 24(1), 115123.

Vásquez, D., \& Navarrete, M. (2010). El maltrato animal. Una reflexión desde la sostenibilidad y las tradiciones culturales. Ingeniería de Recursos Naturales y del Ambiente, 9, 39-43.

Vidal, S. (2010). La bioética en América Latina: el programa de bioética de la UNESCO para la Región (Estudios y documentos de política científica de ALC, Vol. 2. Ciencia para la paz y el desarrollo: el caso del Juramento Hipocrático para Científicos). Montevideo: UNESCO.

Villaroel, R. (2009). Bioética y reciprocidad en el reconocimiento de derechos y deberes. Acta Bioética, 15(1), 79-86. doi: 10.4067/ S1726-569X2009000100010 
